\title{
TAXAS DE NATALIDADE E MORTALDADE, DIVISIÓN DO TRABALLO E DISTRIBUCIÓN DO TEMPO POR XÉNERO NO MODELO DE CRECEMENTO DE SOLOW
}

\author{
Prof. Wei-Bin ZHANG* \\ Universidade Ritsumeikan do Pacífico Asiático, Xapón
}

Resumo: O obxectivo deste traballo é o de incorporar o modelo de crecemento endóxeno da poboación no modelo de crecemento dun sector de Solow. O estudo propón unha interdependencia dinámica entre a taxa de natalidade, a taxa de mortaldade, a poboación, a acumulación da riqueza, e a distribución do tempo entre traballo, lecer e coidado dos fillos. O aspecto da produción e acumulación de riqueza constrúese co modelo de crecemento de Solow. Baseamos o noso modelo de dinámica poboacional no modelo poboacional de Haavelmo e o modelo de elección de fecundidade de Barro-Becker. Resumimos estas forzas dinámicas nun marco compacto, mediante a función de utilidade proposta por Zhang. O modelo describe unha interdependencia dinámica entre cambios da poboación, acumulación de riqueza, división de traballo e a distribución do tempo por xénero entre o traballo, o lecer e o coidado dos fillos. Simulamos o modelo para probar a existencia de puntos de equilibrio e movemento do sistema dinámico. Tamén examinamos os efectos dos cambios nos efectos de cambio na tendencia a ter descendencia, a tendencia ao aforro, a tendencia das mulleres a perseguir actividades de lecer, o capital humano das mulleres e a implicación emocional dos homes no coidado dos fillos.

Palabras chave: tendencia a ter fillos; taxas de natalidade e mortaldade; crecemento da poboación; diferenzas de xénero na distribución do tempo; acumulación da riqueza

\section{Introdución}

A interacción entre o crecemento económico e os cambios na poboación foron un tema chave na economía dende que Malthus publicou Un ensaio sobre o principio da poboación en 1798. A economía moderna experimenta dinámicas poboacionais sen precedentes (como o avellentamento e a baixada das taxas de fecundidade nas economías desenvolvidas). En moitas partes do mundo a expectativa de vida aumentou dramaticamente. Este estudo examina as interaccións dinámicas entre a acumulación de riqueza e as dinámicas poboacionais con taxas endóxenas de nacemento e mortaldade. Os aspectos económicos desde traballo están fortemente influídos pola teoría de crecemento neoclásica. O ensaio máis influínte neste campo é o modelo de Solow. A súa teoría céntrase sobre todo no capital físico endóxeno ou a acumulación de riqueza (Solow, 1956; Burmeister e Dobell, 1970; Azariadis, 1993; Barro e Sala-i-Martin, 1995). O modelo deste estudo constrúese no marco da teoría de crecemento neoclásica. Seguimos o modelo de Solow en canto ao modelo de produción económica e acumulación de riqueza. Porén, analizamos o comportamento no fogar segundo as formulacións propostas por Zhang (1993).

O obxectivo desde artigo é o de incorporar a taxa de natalidade e a taxa de mortaldade no modelo de crecemento dun sector de Solow. Cando analizamos os cambios poboacionais (sen inmigración internacional), necesitamos considerar as taxas de natalidade e

\footnotetext{
* Prof. Wei-Bin Zhang, Universidade Ritsumeikan do Pacífico Asiático. Jumonjibaru, Beppu-Shi, Oitaken、874-8577 Xapón. E-mail: wbz1@apu.ac.jp)

Recoñecementos: $\mathrm{O}$ autor agradece os comentarios construtivos da catedrática e editora MaríaCarmen Guisán. O autor tamén agradece o apoio financeiro do Fondo de Investigación para a Universidade Ritsumeikan do Pacífico Asiático no ano 2014.
} 
mortaldade. Podemos atopar moitos factores, como os cambios na diferenza dos salarios por xénero (Galor e Weil, 1996), as friccións no mercado laboral (Adsera, 2005), e a estrutura de idade (Hock e Weil, 2012), que afectan á fecundidade. Hai moitos estudos sobre a interdependencia entre o crecemento da economía e a fecundidade. Por exemplo, Barro e Becker (1989) examinan unha correlación entre a fecundidade endóxena e o crecemento da economía nun modelo de xeracións traslapadas. Conforme a Becker et al. (1990), criar fillos ata a idade adulta e darlles unha formación é algo gravoso xa que hai unha relación de calidade-cantidade con respecto aos fillos. Na súa análise, o crecemento só é o resultado da acumulación do capital humano. Nas aproximacións de Galor e Weil (1999) e Doepke (2004), a relación calidade-cantidade para os fillos foi tratada como un factor que afecta á transición das economías dende unha etapa de estancamento ata unha de crecemento continuo. Bosi e Seegmuller (2012) estudaron a heteroxeneidade dos fogares en canto á renda dispoñible, mortaldade, e custo por fillo sobrevivente. O modelo estuda a relación cantidade-calidade de ter fillos, resumido polo axuste do custo medio para criar cada fillo sobrevivente. Conforme á súa análise, un aumento da mortaldade aumenta o custo no tempo por fillo sobrevivente e aumenta o crecemento económico. $\mathrm{O}$ modelo de crecemento de Schumpeter coa fecundidade endóxena e a acumulación de capital humano é o proposto por Chu et al. (2012). Varvarigos e Zakaria (2013) examinan as correlacións entre as escollas de fecundidade e os gastos en saúde no marco tradicional de xeracións traslapadas. O seu modelo está influído polas análises de Bhattacharya e Qiao (2007), e Manuelli e Seshadri (2009) sobre fecundidade e gastos en saúde. O modelo de Varvarigos e Zakaria predí o descenso da fecundidade xunto co proceso de crecemento económico. O modelo de xeracións traslapadas de dous períodos de Strulik (2008) considera o consumo de subsistencia e a supervivencia infantil. O modelo predí unha correlación invertida en forma de U entre a fecundidade e a renda. A medida que a familia ten máis ingresos, tamén ten máis recursos para criar os fillos. Por outra banda, a máis ingresos, máis adican os pais e nais a recursos para o coidado dos fillos. Acemoglu e Johnson (2007) tratan de analizar o impacto da expectativa de vida no crecemento económico. Non hai probas de que se identificara un efecto positivo. Tamén se observa que hai un descenso da taxa de fecundidade xunto co proceso de desenvolvemento económico (p. ex., Kirk, 1996; Ehrlich e Lui 1997; Galor, 2012).

O avellentamento converteuse nunha enorme preocupación para moitas das economías modernas. Dada a estrutura da poboación, o avellentamento está intimamente relacionado coa taxa de mortaldade. Polo tanto, convén entender os mecanismos sociais e económicos da mortaldade. Robinson e Srinivasan (1997) centran a súa atención na alta relación da taxa de mortaldade para o desenvolvemento da economía. Lancia e Prarolo (2012) propoñen un modelo de lonxevidade da vida e desenvolvemento económico. O modelo de xeración traslapada de tres períodos considera as decisións dos axentes en dous aspectos: unha escolla privada para a educación e unha escolla pública para as políticas de innovación. Pódense atopar moitos estudos e relacións entre os modelos de crecemento económico e a lonxevidade endóxena (p. ex., Blackburn e Cipriani, 2002; Chakraborty, 2004; Hazan e Zoabi, 2006; Balestra e Dottori, 2012). Segundo Schultz (1993, 1998), a expectativa de vida dos fillos aumenta conforme á educación e o capital humano dos pais. Balestra e Dottori (2012) constrúen un modelo de crecemento de lonxevidade endóxena nun modelo OLG de equilibrio xeral para as subministracións públicas de sanidade e protección medioambiental. Tamén hai moita literatura de estudos sobre o impacto da dependencia da vellez na fecundidade a través do sistema de pensións (Cigno e Rosati, 1996; Wigger, 1999). Hock e Weil (2012) examinan a interdependencia entre a fecundidade e a estrutura de idade da poboación que xorde da dependencia económica na presenza de transferencias interxeracionais. Amosan unha posible dinámica na que a 
crecente dependencia dos anciáns fan que a renda dispoñible da poboación activa baixe, provocando unha menor fecundidade e máis avellentamento da poboación. Hai moitos modelos teóricos sobre a loxevidade (p. ex., Boucekkine et al. 2002; Kalemli-Ozcan et al., 2000; Echevarria e Iza, 2006; Heijdra e Romp, 2008; Ludwig e Vogel, 2009; Lee e Mason, 2010; e Ludwig et al., 2012).

Algúns dos datos dos estudos empíricos da relación entre o crecemento natural da poboación e o desenvolvemento internacional son os seguintes: 1) A taxa de fecundidade descende coa educación e aumenta coa renda per cápita. Como amosaron Guisán, Aguayo e Expósito (2001), cunha mostra empírica de 132 países, o nivel educativo medio dos pais baixan as taxas de fecundidade media das mulleres porque as familias tenden a axustar 0 número de fillos ao seu desexo e capacidade de ingresos, e baixo estas condicións, só un pequeno número de familias decidirían ter moitos fillos. Ademais, o aumento da renda per cápita, nun nivel educativo determinado, a miúdo ten un impacto un chisco positivo no desexo e capacidade financeira para aumentar o número de fillos na familia. 2) Conforme a Guisán e Neira (2006) e outros estudos, hai un importante impacto positivo do nivel educativo da poboación na renda per cápita, cunha retroalimentación xa que o desenvolvemento normalmente axuda a aumentar o nivel educativo da poboación. 3) O efecto total da educación adoita derivar en evitar taxas de fecundidade excesivas e favorecen o desenvolvemento económico: o impacto da educación na fecundidade (diminución) habitualmente é máis alto que o impacto da renda sobre a fecundidade (aumento), o cal leva a unha moderación no aumento da poboación e favorece o aumento da cantidade de capital por cabeza e produción por cabeza.

O noso estudo segue a literatura sobre a teoría de crecemento neoclásica e a literatura sobre o crecemento da poboación e o desenvolvemento económico. Unha contribución única neste traballo é o modelo de crecemento da poboación no marco do modelo de crecemento de Solow cunha acumulación da riqueza endóxena e unha distribución do tempo por xénero entre traballo, lecer e coidados dos fillos. $\mathrm{O}$ artigo analiza a relación entre o crecemento da riqueza, o crecemento económico, a división do traballo por xénero e o crecemento da poboación. A acumulación física de capital constrúese co modelo de crecemento de Solow. As dinámicas das taxas de nacemento e mortaldade seguen 0 modelo poboacional de Haavelmo e o modelo de escollas de fecundidade de Barro-Becker. Resumimos estes mecanismos dinámicos nun marco compacto, aplicando unha función de utilidade alternativa proposta por Zhang (1993). O modelo vén a ser un resumo dos dous modelos de Zhang. Zhang (2012) desenvolve un modelo de crecemento económico cunha división do traballo por xénero, pero asumindo unha poboación constante. Este artigo introduce as taxas de nacemento e mortaldade endóxenas neste modelo. Zhang (2014) desenvolve un modelo de crecemento coa poboación endóxena sen considerar cuestións de xénero. Este estudo introduce a distribución do tempo por xénero entre o traballo, o lecer e o coidado dos fillos no modelo. Concretamente, xeneralizamos as dinámicas de poboación de Zhang, considerando os custos de tempo adicado ao coidado dos nenos neste estudo. $\mathrm{O}$ traballo organízase do seguinte xeito: o Apartado 2 introduce o modelo básico cunha acumulación da riqueza e do capital humano con subsidios do goberno en educación. O Apartado 3 simula o modelo. O Apartado 4 realiza unha análise dinámica comparativa con respecto a algúns dos parámetros. O Apartado 5 amosa as conclusións do estudo.

\section{0 modelo básico}

O sector de produción está baseado no modelo de crecemento de Solow (Solow, 1956). Conta cun sector, producindo un só produto para o consumo e o investimento. O capital 
depréciase nunha taxa exponencial constante, $\delta_{k}$, que é independente da maneira de uso. A tecnoloxía do sector produtivo está caracterizada por redementos constantes a escala. Todos os mercados son perfectamente competitivos. Os factores son subministrados inelasticamente e os factores dispoñibles utilízanse por completo en todo momento. Os aforros só se teñen en conta por fogares. Todas as rendas de empresas distribúense en forma de pagos a factores de produción. Os fogares teñen os activos da economía e distribúen a súa renda en consumo, ter fillos e a acumulación da riqueza. A poboación de cada xénero é homoxénea. Asumimos que cada familia consta de marido, muller e fillos. Todas as familias son idénticas. Usamos os subíndices $q=1$ e $q=2$ para representar aos homes e ás mulleres respectivamente. Usamos $N(t)$ para representar a poboación de cada xénero. $T_{q}(t)$ e $\bar{T}_{q}(t)$ representan o tempo adicado ao traballo e o tempo adicado ao coidado dos fillos do xénero $q \mathrm{e} \bar{N}(t)$ o caudal de servizos laborais usados nun tempo $t$ para a produción. Temos $\bar{N}(t)$

$$
\bar{N}(t)=\left[h_{1} T_{1}(t)+h_{2} T_{2}\right] N(t)
$$

onde ${ }^{h} q$ é o nivel de capital humano do xénero $q$.

\section{0 sector de bens do capital}

O sector de produción usa o capital e o traballo como variables. $K(t)$ representa o total de capital nun momento $t$. Usamos $F(t)$ para representar o nivel de produción. A función de produción é

$$
F(t)=A K^{\alpha}(t) \bar{N}^{\beta}(t), \alpha, \beta>0, \alpha+\beta=1,
$$

onde $A, \alpha$, e $\beta$ son os parámetros. Os mercados son competitivos, polo tanto o traballo e o capital gañan os seus produtos marxinais e as empresas gañan beneficios cero. Representamos as taxas de interese e de salarios por unidade de tempo, ${ }^{r}(t) \mathrm{e} w(t)$, respectivamente. Para unha empresa individual, $r(t) \mathrm{e} w(t)$ danse en calquera momento no tempo. O sector de produción elixe $K(t)$ e $\bar{N}(t)$ para maximizar os beneficios. As condicións marxinais son:

(3)

$$
r(t)+\delta_{k}=\frac{\alpha F(t)}{K(t)}, w(t)=\frac{\beta F(t)}{\bar{N}(t)}, \quad w_{q}(t)=h_{q} w(t)
$$

\section{Comportamentos dos consumidores}

Os consumidores deciden a distribución do tempo, o nivel de consumo dos produtos, 0 número de fillos e as cantidades a aforrar. A diferenza dunha teoría de crecemento óptima na que se usan ondas de consumo futuro definido por utilidade, usamos unha formulación alternativa para os fogares proposta por Zhang (1993). Para describir o comportamento 
dos consumidores, consideramos $\bar{k}(t)$, a riqueza das familias, onde $\bar{k}(t)=K(t) / N(t)$. Os ingresos actuais por unidade familiar dos pagos de intereses e salarios é o seguinte:

$$
y(t)=r(t) \bar{k}(t)+\left[h_{1} T_{1}(t)+h_{2} T_{2}(t)\right] w(t)
$$

Chamamos $y(t)$ aos ingresos reais no senso de que proveñen dos pagos dos consumidores por obras e servizos e as rendas reais dos consumidores que proveñen da propiedade de riqueza. $\mathrm{O}$ valor total da riqueza que a familia pode vender para mercar bens e para aforrar é igual a $\bar{k}(t)$. Neste caso asumimos que a compra e venda de riqueza pódese realizar de forma instantánea sen custo de transacción. A renda dispoñible por familia determínase por

$$
\hat{y}(t)=y(t)+\bar{k}(t)
$$

$n(t)_{\mathrm{e}} p_{b}(t)$ representan a taxa de natalidade e o custo do nacemento en cada momento. Hai moitos factores que poden afectar o custo da crianza dos fillos. Conforme a Zhang (2014), consideramos que os fillos teñen o mesmo nivel de riqueza que o dos pais. A maiores do tempo que adican aos fillos, o gasto dos pais exprésase como

$$
p_{b}(t)=n(t) \bar{k}(t)
$$

Neste caso, ignoramos outros gastos como compras por produtos e servizos. No modelo de escolla de fecundidade de Barro e Becker (1989), o gasto inclúe tamén o consumo de produtos. Nós introducimos o tempo adicado aos fillos. Becker (1981) pon énfase no gasto do tempo da nai para criar aos fillos ata a idade adulta. Nalgunhas sociedades, as mulleres son as que coidan dos nenos maioritariamente. Consideramos a seguinte relación entre a taxa de fecundidade o o tempo que os pais e as nais adican ao coidado dos nenos

$$
\bar{T}_{q}(t)=\theta_{q} n(t), \theta_{q} \geq 0
$$

A función específica implica a suposición de que se os pais queren ter máis fillos, adican máis tempo ao coidado dos fillos. Este requisito é estrito xa que o coidado dos fillos normalmente xera rendementos constantes a escala . Por exemplo, o tempo adicado aos fillos por neno adoita baixar a medida que a familia ten máis fillos. Necesitamos uns rendementos constantes a escala porque deste xeito a suposición fai que a análise sexa tratable matematicamente.

O fogar distribúe o orzamento dispoñible total entre os aforros, $s(t)$, o consumo de bens, $c(t)$, e o coidado dos fillos, $p_{b}(t)$. A reserva de orzamento é

$$
p(t) c(t)+s(t)+\bar{k}(t) n(t)=\hat{y}(t)
$$

Consideramos que a maiores do traballo e o coidado dos fillos, os pais tamén adican tempo ao lecer. Representamos o tempo de lecer por xénero $q$ como $\widetilde{T}_{q}(t)$. Un adulto encara a seguinte limitación de tempo

$$
T_{q}(t)+\bar{T}_{q}(t)+\widetilde{T}_{q}(t)=T_{0}
$$


onde $T_{0}$ é o tempo total dispoñible para o lecer, o traballo e o coidado dos fillos. Se substituímos (8) por (7), obtemos

$$
p(t) c(t)+s(t)+\bar{k}(t) n(t)+\bar{T}_{1}(t) w_{1}(t)+\bar{T}_{2}(t) w_{2}(t)+\widetilde{T}_{1}(t) w_{1}(t)+\widetilde{T}_{2}(t) w_{2}(t)=\bar{y}(t)
$$

onde

$$
\bar{y}(t) \equiv(1+r(t)) \bar{k}(t)+\left(w_{1}(t)+w_{2}(t)\right) r_{0} .
$$

O lado dereito é a renda "potencial" que a familia pode obter ao pasar todo o tempo dispoñible no traballo. O lado esquerdo é a suma dos gastos de consumo, aforros, o custo de oportunidade do coidado dos fillos e o custo de oportunidade do lecer. Ao incorporar (6) en (9), obtemos

$$
c(t)+s(t)+\widetilde{w}(t) h(t)+\widetilde{T}_{1}(t) w_{1}(t)+\widetilde{T}_{2}(t) w_{2}(t)=\bar{y}(t),
$$

onde

$$
\widetilde{w}(t) \equiv \bar{k}(t)+h w(t), \quad h \equiv \theta_{1} h_{1}+\theta_{2} h_{2} .
$$

A variable $\widetilde{w}(t)$ é o custo de oportunidade do coidado dos fillos. Como Barro e Becker (1989), asumimos que a utilidade dos pais depende do número de fillos. Supoñemos que a utilidade é dependente en $c(t), s(t), \widetilde{T}_{q}(t), \mathrm{e}^{n(t)}$ do seguinte xeito

$$
U(t)=c^{\xi_{0}}(t) s^{\lambda_{0}}(t) \widetilde{T}_{1}^{\sigma_{01}}(t) \widetilde{T}_{2}^{\sigma_{02}}(t) n^{v_{0}}(t)
$$

onde $\xi_{0}$ refírese á tendencia a consumir, ${ }^{\lambda}$ á tendencia a ter riqueza, $\sigma_{0 q}$ a tendencia do xénero $q^{\prime} s$ a usar tempo de lecer, e $v_{0}$ á tendencia a ter fillos. Cabe sinalar que neste estudo supoñemos que a utilidade dos pais só depende do número de fillos. Conforme a Soares (2005), a utilidade dos pais non só depende dos fillos sobreviventes, senón tamén da duración da vida de cada fillo que sobrevive. A condición de primeira orde para maximizar $U(t)$ suxeito a (13) dá

$$
c(t)=\xi \bar{y}(t), s(t)=\lambda \bar{y}(t), \widetilde{T}_{q}(t)=\frac{\sigma_{q} \bar{y}(t)}{w_{q}(t)}, n(t)=\frac{v \bar{y}(t)}{\widetilde{w}(t)},
$$

onde

$$
\xi \equiv \rho \xi_{0}, \lambda \equiv \rho \lambda_{0}, \sigma_{q} \equiv \rho \sigma_{q 0}, v \equiv \rho v_{0}, \rho \equiv \frac{1}{\xi_{0}+\lambda_{0}+\sigma_{10}+\sigma_{20}+v_{0}} .
$$

Observamos que o gasto en cada punto é igual ao gasto dispoñible potencial por tendencia a consumir en cada punto. A partir de (10), chegamos a

$$
\frac{\widetilde{T}_{1}(t)}{\widetilde{T}_{2}(t)}=\frac{\sigma_{1} h_{2}}{\sigma_{2} h_{1}}
$$


Comprobamos que a proporción de tempo de lecer entre o home e a muller están correlacionados positivamente coa proporción da tendencia do home e da muller a quedar na casa e negativamente co capital humano do home e da muller. No noso modelo, ignoramos calquera discriminación por xénero posible. A ecuación anterior é o reflexo desta suposición. É importante incorporar cuestións de discriminación por xénero, diferenzas de xénero nos beneficios dos investimentos do capital humano (por exemplo, Folbre, 2009). Dende un punto de vista analítico, é doado considerar algúns (tipos de) discriminación por xénero no mercado laboral. Conforme a Antecol (2000), hai unha variación substancial nas diferenzas por xénero das taxas de participación no mercado de traballo (LFPR) en todos os países. "As diferenzas por xénero na LFPR, que son a LFPR do homes menos a LFPR das mulleres, varía dende 89.4 puntos porcentuais en Afghanistán, 50.6 puntos porcentuais en Grecia, ata 2.2 puntos porcentuais en Suecia. Sorprendentemente, hai poucos artigos entre economistas que tratan de explicar a variación entre países nas taxas de participación no mercado de traballo por parte das mulleres". A ecuación anterior amosa que as diferenzas de xénero na tendencia a traballar e en capital humano debería afectar o tempo das mulleres adicado ao traballo. Este estudo supón que a preferencia é constante. Sería razoable considerar ás tendencias endóxenas. As preferencias endóxenas debería axudar a explicar os complicados patróns da división do tempo por xénero (p. ex., Goodfriend e McDermott, 1995; Kelly, 1997; Edmonds e Pavcnik, 2006). É conceptualmente posible considerar os cambios de preferencias endóxenas ao introducir correctamente as tendencias relacionadas con rendas, salarios e outros factores, do seguinte modo $d(\mathbb{d})=G(w, y, \ldots)$, onde $\mathrm{G}$ é a función dos diferentes factores que se especifican.

\section{Taxas de nacemento e mortaldade e dinámicas poboacionais}

Para ilustrar a nosa formulación e amosar como o noso modelo se relaciona coa literatura, seguimos o modelo de Haavelmo (Haavelmo, 1954; Stutzer, 1980)

$$
\text { 周 })=N(t)\left(a-\frac{\beta N(t)}{Y(t)}\right), a, \beta>0, \quad Y(t)=A N^{\alpha}(t), A>0,0<\alpha<1,
$$

onde $N(t)$ é a poboación, $Y(t)$ é a produción real, e $a, \beta, \alpha$ e $A$ son os parámetros. Engadimos $Y(t)=A N^{\alpha}(t)$ na ecuación diferencial

$$
\frac{\sqrt{\text { 冏 }})}{N(t)}=a-\frac{\beta}{f(t)}=a-\frac{\beta N^{1-\alpha}(t)}{A} \text {, }
$$

onde $f \equiv Y / N$ é a produción per cápita. No modelo de Haavelmo, non hai acumulación de capital físico. Como a taxa de cambios na poboación correspóndese á taxa de natalidade menos a taxa de mortaldade, podemos interpretar que no modelo de Haavelmo, a taxa de natalidade $(=a)$ é constante e a taxa de mortaldade $(=\beta / f(t)$ ) está negativamente correlacionada coa renda per cápita.

Outra aproximación típica na literatura sobre o crecemento poboacional e o desenvolvemento económico é o chamado modelo de Ramsey. Un exemplo é o modelo de Chu et al. (2012). O fogar decide a taxa de fecundidade maximizando a suma descontada da utilidade per cápita conformeá acumulación de recursos 


$$
\begin{aligned}
& U=\int_{0}^{\infty} u(c(t), n(t)) e^{-\rho t} d t, \\
& \text { s.t.: }(r(t)-n(t)) a(t)+w(t) l(t)-c(t),
\end{aligned}
$$

onde $c(t)$ é o consumo per cápita de produtos elaborados nun momento $t, n(t)$ é o número de nacementos por persoa, $a(t)$ é a cantidade de activos financeiros per cápita, $r(t)$ é a taxa de beneficios dos activos, $w(t)$ é a taxa de salarios, e $l(t)$ é o subministro de traballo realizado polo capital humano. O crecemento total da poboación é $\sqrt{\mathrm{W}} n N$. Como a mortaldade figura como cero neste modelo, $n$ tamén é a taxa de crecemento da poboación. O tipo de crecemento da poboación tamén se acepta, por exemplo, por Razin e Ben-Zion (1975) e Yip e Zhang (1997).

Conforme ás definicións, o cambio poboacional segue a ecuación

$$
\sqrt{(x)})=(n(t)-d(t)) N(t)
$$

onde $n(t) \mathrm{e} d(t)$ son a taxa de natalidade e a taxa de mortaldade respectivamente. Cabe sinalar que Tournemaine e Luangaram (2012) constrúen un modelo de crecemento poboacional e de desenvolvemento económico. Nel, examinan as relacións entre a fecundidade, a educación, as taxas de crecemento por cambios técnicos e da renda per cápita. Usan a seguinte tecnoloxía de produción no caso dos fillos: $n(t)=b T_{b}^{\ominus}(t)$, onde $T_{b}(t)$ é o tempo adicado á criar un fillo e $b$ e $\theta$ son os parámetros. No seu modelo, a taxa de mortaldade usada é constante. $\mathrm{O}$ noso modelo introduce a taxa de mortaldade endóxena. No modelo de Haavelmo, a taxa de mortaldade está negativamente correlacionada coa renda per cápita. Neste estudo, supoñemos que a taxa de mortaldade está negativamente correlacionada coa renda dispoñible do seguinte modo

$$
d(t)=\frac{\bar{v} N^{b}(t)}{\bar{y}^{a}(t)}
$$

onde $\bar{v} \geq 0, a \geq 0$. Chamamos $\bar{v}$ ao parámetro da taxa de mortaldade. Como ocorre no modelo de Haavelmo, unha mellora nas condicións de vida implica que a xente vive máis tempo. $N^{b}(t)$ ten en conta posibles impacto da mortaldade na poboación. Por exemplo, cando hai superpoboación, o medioambiente se deteriora. Este termo ten en conta este tipo de efecto sobre o medioambiente. Neste caso, é razoable requirir que $b$ sexa positivo. Convén sinalar que o signo do parámetro é xeralmente ambiguo no senso que a poboación tamén pode ter un impacto positivo sobre a mortaldade. Engadimos (10) e (13) en (12)

$$
\sqrt{2})=\left(\frac{v \bar{y}(t)}{\widetilde{w}(t)}-\frac{\bar{v} N^{b}(t)}{\bar{y}^{a}(t)}\right) N(t) \text {. }
$$

A ecuación describe as dinámicas da poboación. Hai que destacar que para describir os cambios poboacionais axeitadamente, no modelo non só hai que ter en conta as dinámicas 
de nacementos e mortaldade, senón tamén a estrutura de idade. Como na meirande parte dos modelos da literaratura referidos a un tempo continuado de crecemento económico e cambios poboacionais, e para simplificar a análise, non tratamos cuestións complicadas relacionadas coa estrutura de idade.

\section{Dinámica da riqueza}

Aquí obtemos as dinámicas da acumulación de riqueza. Conforme á definición de $s(t)$, 0 cambio de riqueza nos fogares, obtense mediante

$$
\bar{k}(t)=s(t)-\bar{k}(t)=\lambda \bar{y}(t)-\bar{k}(t)
$$

\section{Demanda e oferta de produtos}

Os aforros nacionais son a suma dos aforros dos fogares. Como o resultado do sector de bens de capital é igual aos aforros netos e a depreciación do total de capital, temos

$$
S(t)+C(t)-K(t)+\delta_{k} K(t)=F(t)
$$

onde $S(t)-K(t)+\delta_{k} K(t)$ é a suma dos aforros netos e a depreciación e

$$
S(t)=s(t) N(t), C(t)=c(t) N(t), K(t)=\bar{k}(t) N(t)
$$

Como consecuencia construímos o modelo dinámico. Cabe sinalar que o modelo é xeral no senso que o modelo de Solow e o modelo de Haavelmo pódense considerar casos especiais do noso modelo. Ademais, como o noso modelo está baseado nalgúns dos modelos matemáticos máis coñecidos e inclúe algunhas características que ningún outro modelo teórico explica, deberíamos poder explicar algunhas das relacións que outros modelos formais non o fan. A continuación, examinamos as dinámicas do modelo.

\section{As dinámicas e as súas propiedades}

Esta sección examina as dinámicas do modelo. Primeiro, introducimos $z(t) \equiv\left(r(t)+\delta_{k}\right) / w(t)$. Amosamos que as dinámicas pódense expresar mediante un sistema de dúas ecuacións diferenciais con $z(t) \mathrm{e} N(t)$ como variables.

\section{Lema 1}

As dinámicas do sistema económico está gobernado por dúas ecuacións diferenciais

$$
\begin{aligned}
& t(t)=\widetilde{\Omega}_{z}(z(t), N(t)), \\
& \sqrt{(2})=\widetilde{\Omega}_{N}(z(t), N(t)),
\end{aligned}
$$

onde as funcións $\widetilde{\Omega}_{z}$ e $\widetilde{\Omega}_{N}$ son as funcións de ${ }^{z(t)}$ e $N(t)$ definidas no Apéndice. Ademais, todas as outras variables están determinadas polas funcións de $z(t) \mathrm{e} N(t)$ en calquera momento dado no tempo mediante o seguiente procedemento: $\bar{k}(t)$ por (A11) $\rightarrow$

$$
\begin{aligned}
& r(t) \mathrm{e}^{w_{q}(t)} \text { por (A2) } \rightarrow \bar{N}(t) \text { por (A16) } \rightarrow \bar{y}(t) \text { por (A3) } \rightarrow c(t), s(t), \tilde{T}_{q}(t), \mathrm{e}^{n(t)} \\
& \operatorname{por}(11) \rightarrow \bar{T}_{q}(t) \operatorname{por}(6) \rightarrow T_{q}(t) \text { por (A4) } \rightarrow K(t)_{\text {por (A1) } \rightarrow} F(t) \text { por (2). }
\end{aligned}
$$


O sistema de ecuacións diferenciais (17) ten dúas variables, $z(t)$ e $N(t)$. Como amosamos no Apéndice, as expresións son complicadas. É difícil interpretar explicitamente as implicacións económicas das dúas ecuacións. Simulamos o modelo para ilustrar o comportamento do sistema. No resto deste estudo, especificamos a taxa de depreciación con $\delta_{k}=0.05$, e $T_{0}=24$. Especificamos os outros parámetros como segue

$$
\begin{aligned}
& a=0.34, \lambda_{0}=0.6, \xi_{0}=0.3, v_{0}=0.4, \sigma_{10}=0.16, \sigma_{10}=0.16, A=1, a=0.2, b=0.2, \\
& h_{1}=5, h_{2}=4.5, \theta_{1}=2, \theta_{2}=5, \bar{v}=1 .
\end{aligned}
$$

A tendencia a aforrar é de 0.6 e a tendencia a consumir é de 0.3 . O factor de produtividade total é $A=1$. Neste caso, as nais adican máis horas ao coidado dos fillos cos pais. Tanto o pai como a nai teñen certa tendencia á realizar actividades de lecer. $\mathrm{O}$ capital humano dos pais é máis alto co das nais. Sinalamos que os valores específicos non están baseados en observacións empíricas e a escolla semella realista. Por exemplo, algúns estudos empíricos da economía dos Estados Unidos proban que o valor do parámetro $\alpha$, no modelo de produción de Cobb-Douglas é aproximadamente igual a 0.3 (por exemplo, Miles e Scott, 2005, Abel et al, 2007). Con respecto aos parámetros de preferencia, o que importa no noso estudo son os seus valores relativos. Para seguir os movementos no sistema, especificamos as seguintes condicións iniciais

$$
z(0)=1.4, N(0)=16
$$

O resultado da simulación aparece representado na Figura 1. A poboación crece dende unha condición inicial baixa. A medida que crece a poboación, a taxa de mortaldade tamén crece. A man de obra crece e baixan os salarios. A redución dos salarios diminúe o custo de oportunidade de criar fillos, e o resultado é un aumento da taxa de natalidade. A medida que baixan os ingresos, os homes e as mulleres traballan máis horas e as horas de lecer baixan. A riqueza e a produción nacional aumentan en relación co aumento da man de obra. Porén, tanto o nivel de consumo como a riqueza por fogar baixan.

É sinxelo confirmar que todas as variables chegan a un punto de estancamento a longo prazo. Isto implica a existencia dun punto de equilibrio. A simulación confirma que o sistema ten un equilibrio único. Atopamos os seguintes valores de equilibrio nas variables

$$
\begin{aligned}
& N=18.67, K=456.13, \bar{N}=1580.45, F=1035.82, n=d=0.56, \quad r=0.72, \\
& w_{1}=2.16, w_{2}=1.95, \tilde{w}=114.91, \bar{k}=100.85, T_{1}=10.40, T_{2}=7.26, \widetilde{T}_{1}=12.44, \widetilde{T}_{2}=13.82, \\
& \quad T_{1}=1.17, \bar{T}_{2}=2.93, c=50.43 .
\end{aligned}
$$

Calculamos dous valores propios: $-0.41 \mathrm{e}^{-0.12}$. Como os dous valores propios son negativos, o equilibrio único é localmente estable. Polo tanto, o sistema sempre se achega ao seu equilibrio se non está alonxado do equilibrio.

\section{Análise dinámica comparativa nalgúns parámetros da simulación}

Baixo (18) simulamos os movementos da economía nacional. Agora examinamos as reaccións do sistema económico perante os cambios exóxenos. Como o lema proporciona o procedemento computacional para calibrar o cambio das variables, é sinxelo examinar os efectos dos cambios en calquera parámetro en procesos transitorios e tamén en etapas 
de estancamento de todas as variables. Usamos a variable ${ }^{\bar{\Delta} x_{j}}(t)$ para representar a taxa
de cambio da variable, $x_{j}(t)$, en porcentaxe debido a cambios no valor do parámetro. Un aumento da tendencia a ter fillos

Como describen Tournemaine e Luangaram (2012: 925), "dependendo do país, o crecemento da poboación pode contribuír, deter, o ata non ter ningún impacto no desenvolvemento económico. Este resultado ambiguo pódese explicar polo feito de que os efectos do crecemento da poboación cambia ao longo do tempo. Por exemplo, unha taxa de fecundidade máis alta pode ter un efecto negativo a curto prazo provocado polos custos dos gastos que xeran o coidado dos fillos, mentres que ten un efecto positivo a longo prazo mediante a man de obra máis grande que produce". Pero se sostén que se unha economía nacional non ten unha actividade económica caracterizada por un rendemento a escala crecente, o aumento da poboación tende a reducir as condicións de vida por persoa. Agora examinamos como os diferentes parámetros afectan ao cambio do sistema. Primeiro, estudamos o caso se aumenta a tendencia a ter fillos da seguinte forma: $v_{0}: 0.4 \Rightarrow 0.42$. Os resultados da simulación preséntanse na Figura 2. Para examinar como cada variable está afectada ao longo do tempo, debemos seguir o cambio do sistema enteiro, xa que cada variable está relacionada coas outras no sistema dinámico. Agora amosamos como a economía reacciona ao crecente desexo de ter fillos. Como consta na Figura 2, a taxa de natalidade aumenta, o cal dá como resultado un aumento da poboación. A crecente poboación fai que as condicións sanitarias sexan peor ca antes, polo que a mortaldade aumenta. Observamos que cando as outras condicións son constantes, un pequeno aumento na tendencia a ter fillos ten un grande impacto no crecemento da poboación. $\mathrm{O}$ capital, a cantidade total de man de obra e o nivel de produtividade vense reducidos inicialmente. Os valores destas variables aumentan axiña ao ir aumentando a poboación. A medida que a familia ten máis fillos, os pais adican máis tempo ao seu coidado. Ao principio , aumentan o seu tempo de lecer e reducen as súas horas de traballo. Porén, a medida que baixan os ingresos a longo prazo, deixa de baixar o tempo de traballo. Ter máis fillos implica máis consumo. Cando o cambio da taxa de cambio do capital é máis baixa que a produción, a taxa de interese aumenta ao longo do tempo. Tanto o custo de oportunidade dos fillos $\widetilde{w}$ como o da riqueza por fogar redúcense a longo prazo.

\section{Un aumento da produtividade total dos factores}

A continuación, estudamos como a produtividade total dos factores vese afectada polo crecemento económico. O cambio tecnolóxico no modelo tradicional de Solow ten efectos positivos no crecemento da economía a longo prazo. Como o modelo de Solow supón unha taxa de crecemento constante e uns rendementos a escala constantes, o cambio tecnolóxico non ten impacto sobre a man de obra e a distribución do tempo nin sequera a curto prazo. Agora aumentamos a produtividade total dos factores da seguinte maneira: $A: 1 \Rightarrow 1.05$.

Como mellora a produtividade, o nivel de produtividade e os salarios aumentan. En parte por mor dun crecemento económico positivo, a taxa de natalidade aumenta e a de mortaldade baixa a curto prazo. Os pais adican máis tempo ao coidado dos fillos e a traballar e baixa o seu tempo de lecer. Cando aumenta a poboación, é de esperar que a taxa de mortaldade aumente. A riqueza per cápita e o custo de oportunidade aumentan co tempo. $\mathrm{O}$ aumento do custo da oportunidade fai que a familia reorganice a súa distribución do tempo e redúcese a taxa de natalidade. A longo prazo a distribución do tempo, a taxa de natalidade e a taxa de mortaldade non se ven afectadas polos cambios tecnolóxicos. Convén destacar que este estudo ten en conta os cambios tecnolóxicos na 
produción da economía. Non incluímos os cambios tecnolóxicos relacionados cos coidados de saúde e a innovación médica. Por iso os cambios tecnolóxicos non semellan ter un impacto nas taxas de natalidade e mortaldade a longo prazo no noso modelo baseado no modelo de Solow. En resumo, o cambio tecnolóxico dá como resultado un aumento da saúde nacional, da poboación, da man de obra, dos salarios, dos niveis de consumo e na saúde por fogar, e do custo de oportunidade polo coidado dos fillos. Non ten un impacto a longo prazo na taxa de interese e na distribución do tempo.

\section{Un aumento na tendencia das mulleres a realizar actividades de lecer}

En lugar de traballar e coidar dos fillos, a muller pode elixir realizar actividades de lecer. Xa sabemos que as mulleres aumentan a súa tendencia a aforrar da seguinte maneira: $\sigma_{02}: 0.16 \Rightarrow 0.17$.

Unha consecuencia inmediata neste caso é que a muller adica máis tempo ao lecer e o marido menos. O marido traballa máis e a muller menos. Tanto o marido como a muller reducen o tempo adicado ao coidado dos fillos. Os salarios baixan un chisco. O nivel de consumo, o custo de oportunidade polo coidado dos fillos e a riqueza tamén baixan. Con relación ao impacto neto da redución do custo de oportunidade e a redución da tendencia relativa a ter fillos, a taxa de natalidade baixa. Nun primeiro momento, a taxa de mortaldade sube, pero a longo prazo, baixa. Redúcense a poboación, a man de obra, a riqueza e a produción.

\section{Impacto na tendencia ao aforro}

Conforme ao modelo de Solow, o aumento na tendencia a aforrar aumenta a riqueza per cápita, pero reduce o nivel de consumo per cápita. A taxa de crecemento da poboación non se ve afectada polas condicións económicas neste modelo de crecemento de un sector. A continuación, examinamos o que ocorre na nosa economía con taxas endóxenas de natalidad e mortaldade cando se aumenta a tendencia ao aforro da seguinte maneira: $\lambda_{0}: 0.6 \Rightarrow 0.63$.

A riqueza da familia aumenta a medida que aumenta a súa tendencia ao aforro. Isto provoca un aumento no custo de oportunidade do coidado dos fillos. Un aumento dos custos reduce a taxa de natalidade. Cantos menos fillos teñan as familias, menor é o tempo que se adica ao seu coidado. A medida que aumenta a tendencia ao aforro (que tamén implica unha relativa redución do tempo de lecer), o home e a muller teñen menos tempo de lecer e máis horas de traballo nun primeiro momento. Pero a longo prazo, aumenta o tempo de lecer do home e da muller e, mentres que as horas de traballo dos homes non se ven afectadas, as horas de traballo da muller aumentan. Aumenta o salario e a riqueza, e isto reduce a mortaldade. O impacto neto da redución da natalidade e da mortaldade fai que a poboación baixe. Como consecuencia, a longo prazo baixan tamén a riqueza total, a produción e a man de obra.

\section{A mellora do capital humano das mulleres}

A formulación neoclásica tradicional afirma que as desigualdades de xénero resultado das disparidades no capital humano se esvaecen a medida que a economía experimenta un crecemento alto (p. ex., Beneria e Feldman, 1992, Forsythe, et al. 2000). Conforme a Stotsky (2006: 18), "a formulación neoclásica examina a relación entre o desenvolvemento económico e a redución das desigualdades de xénero. Observa o proceso de desenvolvemento económico que provoca a redución destas desigualdades e tamén desigualdades que impiden o desenvolvemento económico". Conforme a Boserup (1970) hai unha relación curvilínea entre o crecemento económico e o estatus da muller. Boserup mantén que as primeiras etapas de crecemento económico están caracterizadas por unha maior distancia entre o home e a muller. A continuación, analizamos o que ocorre cando aumenta o capital humano da muller da seguinte maneira: $h_{2}: 4.5 \Rightarrow 4.7$. 
A medida que o pai acumula máis capital humano, aumenta o seu salario. A nai gaña máis tempo por unidade e traballa máis. O custo de oportunidade de criar un fillo aumenta a medida que o salario da nai aumenta. Baixa a taxa de natalidade. Os pais adican menos tempo ao coidado dos fillos. A nai traballa máis e o pai menos. O pai ten máis tempo de lecer e a nai menos. O salario do pai vese un chisco afectado. A familia consume máis e ten máis riqueza. A taxa de mortaldade baixa a medida que melloran as condicións de vida. $\mathrm{O}$ impacto neto da redución da taxa de natalidade e de mortaldade aumenta a poboación. $\mathrm{O}$ capital, a man de obra total e a produción aumentan. Convén destacar que moitos estudos proban que a expectativa de vida aumenta segundo o nivel de capital humano agregado ( $\mathrm{p}$. ex., Blackburn e Cipriani, 2002; Boucekkine et al., 2002; Cervellati e Sunde, 2005). O resultado que obtemos confirma esta tendencia se consideramos a taxa de mortaldade correlacionada negativamente con respecto á expectativa de vida. O crecemento positivo da poboación ten un impacto relativamente débil sobre a taxa de natalidade. Se aumenta 0 capital humano da muller e a súa preferencia polo lecer ao mesmo tempo, a taxa de natalidade baixa máis rapidamente que a taxa de mortaldade. Cando iso ocorre, a poboación baixa.

\section{Máis tempo adicado á crianza dos fillos polos pais}

Hai moita literatura empírica e teórica sobre o crecemento económico e a distribución do tempo. Por exemplo, segundo o estudo empírico de Bose et al. (2009) sobre os patróns de traballo das mulleres e os determinantes da división por xénero do traballo rural en Bangladesh, a persistente división do traballo por xénero está asociada a factores económicos e socioculturais. Analizamos teoricamente outro factor que pode chegar a afectar o crecemento económico e a división do traballo por xénero. Partimos da premisa de que o pai adica máis tempo ao coidado dos fillos. Aumentamos o parámetro $\theta_{2}$ así: $\theta_{2}: 1 \Rightarrow 1.05$. Aumenta o tempo que o pai adica ao coidado dos fillos e redúcese un chisco o tempo da nai para a mesma tarefa. Tanto o pai como a nai adican menos tempo ao lecer. A nai traballa máis horas e o pai traballa menos horas. A medida que o pai traballa menos, os ingresos polo salario do pai baixan. A medida que o pai adica máis tempo ao coidado dos fillos, o custo de oportunidade de criar un fillo aumenta. O aumento do custo de oportunidade fai que baixe a taxa de natalidade. Como consecuencia, baixa a poboación e a taxa de mortaldade. A familia ten menos riqueza e baixa a taxa de interese. Aumentan os salarios. Baixa a riqueza total, a man de obra total e a produción. A familia consume menos.

\section{Conclusións}

Este artigo introduce o modelo endóxeno de crecemento da poboación no modelo de crecemento dun sector de Solow. O estudo propón unha interdependencia dinámica entre a taxa de natalidade, a taxa de mortaldade, a poboación, a acumulación da riqueza e a distribución do tempo entre traballo, lecer e coidado dos fillos. Poñemos énfase no rol do capital humano, os cambios tecnolóxicos e de preferencias con respecto ás taxas de natalidade e mortaldade e á distribución do tempo. A nosa formulación segue moitas ideas tradicionais sobre o crecemento o os cambios poboacionais. Tivemos en conta as diferenzas no capital humano, a tendencia a usar tempo de lecer e a eficiencia no coidado dos fillos. Simulamos o modelo para ilustrar os movementos do crecemento económico e os cambios na poboación e atopamos a existencia de puntos de equilibrio.

Tamén estudamos os efectos dos cambios na tendencia a ter fillos, a tendencia ao aforro, a tendencia da muller de usar tempo de lecer, o capital humano das mulleres e a implicación emocional do home no coidado dos fillos. A nosa análise dinámica comparativa aporta datos sobre a correlación entre o crecemento económico e os cambios na poboación. Por 
exemplo, a nosa simulación amosa que se as persoas teñen un forte desexo de ter fillos, aumenta a taxa de natalidade e a poboación; nun primeiro momento baixa o capital, a man de obra total e a produción, pero a longo prazo aumentan; os salarios baixan e a taxa de interese aumenta; os pais adican máis tempo ao coidado dos fillos e consumen menos; e tanto o custo de oportunidade dos fillos como a riqueza por fogar baixan a longo prazo.

Vemos outro resultado cando o pai adica máis tempo ao coidado dos fillos: a nai traballa máis horas e o pai traballa menos horas; baixa o salario do pai e o custo de oportunidade da crianza dos fillos aumenta; a taxa de natalidade e a poboación baixan. Se se reducen os ingresos da familia, a familia ten menos riqueza e consume menos; a taxa de interese baixa e aumentan os salarios; redúcense a riqueza nacional, a man de obra e a produción. Pero se os ingresos familiares non baixan, a familia conta coa mesma riqueza e consume igual ca antes, e os salarios e a riqueza nacional non baixan. Hai moitas posibilidades para xeneralizar e estender o noso modelo, tendo en conta as limitacións e consideracións que incluímos no Apéndice 3.

\section{References}

Abel, A., Bernanke, B.S., and Croushore, D. (2007) Macroeconomics. New Jersey: Prentice Hall.

Acemoglu, D. and Johnson, S. (2007) Disease and Development: The Effect of Life Expectancy on Economic Growth. Journal of Political Economy. 115, 925-85.

Adsera, A. (2005) Vanishing Children: From High Unemployment to Low Fertility in Developed Countries. American Economic Review 95, 189-93.

Antecol, H. (2000) An Examination of Cross-country Differences in the Gender Gap in Labor Force Participation Rates. Labor Economics 7, 409-26.

Azariadis, C. (1993) Intertemporal Macroeconomics. Oxford: Blackwell.

Balestra, C. and Dottori, D. (2012) Aging Society, Health and the Environment.Journal of Population Economics 25, 1045-76.

Bar, M. and Leukhina, O. (2011) On the Time Allocation of Married Couples Since 1960. Journal of Macroeconomics 33, 491-510.

Barro, RJ. and Becker, G.S. (1989) Fertility Choice in a Model of Economic Growth. Econometrica 57, 481-501.

Barro, RJ. and X. Sala-i-Martin (1995) Economic Growth. New York: McGraw-Hill, Inc.

Becker, G. S. (1981) A Treatise on the Family. Cambridge, MA.: Harvard University Press.

Becker, G., Murphy, K. M., and Tamura, R. (1990) Human Capital, Fertility, and Economic Growth," Journal of Political Economy 98, S12-37.

Beneria, L. and Feldman, S. (1992, Eds.) Unequal Burden: Economic Crises, Persistent Poverty, and Women's Work. Boulder: Westview.

Bhattacharya, J. and Qiao, X. (2007) Public and Private Expenditures on Health in a Growth Model. Journal of Economic Dynamics and Control 31, 2519-535.

Blackburn, K. and Cipriani, G.P. (2005) A Model of Longevity, Fertility and Growth. Journal of Economic Dynamics \& Control 26, 187-204.

Bosi, S. and Seegmuller, T. (2012) Mortality Differential and Growth: What Do We Learn from the Barro-Becker Model? Mathematical Population Studies 19, 27-50.

Boucekkine, R., de la Croix, D. and Licandro, O. (2002) Vintage Human Capital, Demographic Trends, and Endogenous Growth. Journal of Economic Growth 104, 340-75.

Bucci, A. (2013) Returns to Specialization, Competition, Population, and Growth. Journal of Economic Dynamics and Control 37, 2023-40.

Burmeister, E. and Dobell, A.R. (1970) Mathematical Theories of Economic Growth. London: Collier Macmillan Publishers.

Chakraborty, S. (2004) Endogenous Lifetime and Economic Growth.Journal of Economic Theory 116, 119-37.

Chu, A.C., Cozzi, G. and Liao, C.H. (2012) Endogenous Fertility and Human Capital in a Schumpeterian Growth Model.Journal of Population Economics (forthcoming) 
Cigno, A. and Rosati, F.C. (1996) Jointly Determined Saving and Fertility Behaviour: Theory and Estimates for Germany, Italy, UK and USA. European Economic Review 40, 1561-89.

Cremers, E.T. (2006) Dynamic Efficiency in the Two-Sector Overlapping Generalizations Model. Journal of Economic Dynamics \& Control 30, 1915-36.

Doepke, M. (2004) Accounting for Fertility Decline During the Transition to Growth. Journal of Economic Growth 9, 347-83.

Echevarria, CA. and Iza, A. (2006) Life Expectancy, Human Capital, Social Security and Growth. Journal of Public Economics 90, 2324-49.

Edmonds, E.V. and Pavcnik, N. (2006) Trade Liberalization and the Allocation of Labor between Households and Markets in a Poor Country. Journal of International Economics 69, 272-95.

Ehrlich, I. and Lui, F. (1997) The Problem of Population and Growth: A Review of the Literature From Malthus to Contemporary Models of Endogenous Population and Endogenous Growth. Journal of Economic Dynamics and Control 21, 205-42.

Folbre, N. (2009) Greed, Lust \& Gender. Oxford: Oxford University Press.

Forsythe, N., Korzeniewicz, R.P. and Durrant, V. (2000) Gender Inequalities and Economic Growth: A Longitudinal Evaluation. Economic Development and Cultural Change 48, 573-617.

Galor, O. (1992) Two-sector Overlapping-generations Model: A Global Characterization of the Dynamical System. Econometrica 60, 1351-86.

Galor, O. and Weil, D.N. (1996) The Gender Gap, Fertility, and Growth. American Economic Review 86, 374-87.

Galor, O. and Weil, D. (1999) From Malthusian Stagnation to Modern Growth. American Economic Review $89,150-54$.

Galor, O. (2012) The Demographic Transition: Causes and Consequences. Cliometrica 6, 1-28

Goodfriend, M. and McDermott,J. (1995) Early Development.American Economic Review 85, 116-33.

Guisan, M.C., Aguayo, E., Exposito, P. (2001). "Economic growth and cycles: Cross-country models of Education, Industry and Fertility and International Comparisons", Applied Econometrics and International Development Vol. 1-1, pp. 9-37: http:/ / www.usc.es/ economet/ eaat.htm

Guisan, M.C., Neira, I. (2006). "Direct and Indirect Effects of Human Capital on World Development, 19602004", Applied Econometrics and International Development Vol. 6-1, pp. 17-34: http:/ / www.usc.es/ economet/ eaat.htm

Haavelmo, T. (1954) A Study in the Theory of Economic Evolution. North-Holland: Amsterdam.

Harrison, S.G. (2003) Returns to Scale and Externalities in the Consumption and Investment Sectors. Review of Economic Dynamics 6, 963-76.

Hazan, M. and Zoabi, H. (2006) Does Longevity Cause Growth? A Theoretical Critique. Journal of Economic Growth 11,363-76.

Heijdra, B.J. and Romp, W.E. (2008) A Life-cycle Overlapping-generaions Model of the Small Open Economy. Oxford Economic Papers 60, 88-121.

Herrendorf, B. and Valentinyi, A. (2006) On the Stability of the Two-Sector Neoclassical Growth Model with Externalities. Journal of Economic Dynamics and Control 30, 1339-61.

Hock, H. and Weil, D.N. (2012) On the Dynamics of the Age Structure, Dependency, and Consumption. Journal of Population Economics 25, 1019-43.

Jensen, B.S. (2003) Walrasian General Equilibrium Allocations and Dynamics in Two-Sector Growth Models. German Economic Review 4, 53-87.

Jensen, B.S. and Lehmijoki, U. (2011) Homothetic Multisector Growth Models, in La Grandville, O. de. (Ed.)

Frontiers of Economics and Globalization, 11. United Kingdom: Emerald.

Kalemli-Ozcan, S., Ryder, H.E., and Weil, D.N. (2000) Mortality Decline, Huma Capital Investment, and Economic Growth. Journal of Development Economics 62, 1-3.

Kelly, M. (1997) The Dynamics of Smithian Growth. Quarterly Journal of Economics 112, 939-64.

Kirk, D. (1996) Demographic Transition Theory. Population Studies 50, 361-87.

Lancia, F. and Prarolo, G. (2012) A Politico-Economic Model of Aging, Technology Adoption and Growth. Journal of Population Economics 25, 989-1018. 
Lee, R. and Mason, A. (2010) Fertility, Human Capital, and Economic Growth over the Demographic Transition. European Journal of Population 26, 159-82.

Li, J.L. and Lin S.L. (2008) Existence and Uniqueness of Steady-State Equilibrium in a Two-Sector Overlapping Generations Model. Journal of Economic Theory 141, 255-75.

Ludwig, A. and Vogel, E. (2009) Mortality, Fertility, Education and Capital Accumulation in a Simple OLG Economy. Journal of Population Economics 23, 703-35.

Ludwig, A., Schelkle, T., and Vogel, E. (2012) Demographic Change, Human Capital and Welfare. Review of Economic Dynamics 15, 94-107.

Manuelli, R.E. and Seshadri, A. (2009) Explaining International Fertility Differences. Quarterly Journal of Economics 124, 771-807.

Miles, D. and Scott, A. (2005) Macroeconomics - Understanding the Wealth o Nations. Chichester: John Wiley \& Sons, Ltd.

Razin, A. and Ben-Zion, U. (1975) An Intergenerational Model of Population Growth. American Economic Review 65, 923-33.

Robinson, J.A. and Srinivasan, T.N. (1997) Long-term Consequence of Population Growth: Technological Change, Natural Resources, and the Environment, in Handbook of Population and Family Economics, edited by Rozenzweig, M.R. and Stark, O. Amsterdam: North-Holland.

Schultz, P.T. (1993) Mortality Decline in the Low-Income World: Causes and Consequences. American Economic Review 83, 337-42.

Schultz, P.T.(1998) Health and Schooling Investments in Africa.The Journal of Economic Perspectives 13, 67-88.

Soares, R.R. (2005) Mortality Reductions, Educational Attainment, and Fertility Choice. American Economic Review 95, 580-601.

Solow, R. (1956) A Contribution to the Theory of Growth. Quarterly Journal of Economics 70, 65-94.

Stockman, D.R. (2009) Chaos and Sector-Specific Externalities. Journal of Economic Dynamics and Control 33, 2030-46.

Stotsky, J.G. (2006) Gender and Its Relevance to Macroeconomic Policy: A Survey. IMF Working Paper, WP/ 06/ 233.

Strulik, H. (2008) Geography, Health, and the Pace of Demo-Economic Development. Journal of Development Economics 86, 61-75.

Stutzer, M. (1980) Chaotic Dynamics and Bifurcation in a Macro Economics. Journal of Economic Dynamics and Control 2, 253-73.

Tournemaine, F. and Luangaram, P. (2012) R\&D, Human Capital, Fertility, and Growth. Journal of Population Economics 25, 923-53.

Uzawa, H. (1961) On a Two-Sector Model of Economic Growth. Review of Economic Studies 29, 47-70.

Uzawa, H. (1963) On a Two-Sector Model of Economic Growth I. Review of Economic Studies 30, 105-18.

Varvarigos, D. and Zakaria, I.Z. (2013) Endogenous Fertility in a Growth Model with Public and Private Health Expenditures. Journal of Population Economics 26, 67-85.

Wigger, B.U. (1999) Pay-as-you-go Financed Public Pensions in Model of Endogenous Growth and Fertility. Journal of Population Economics 12, 625-40.

Yip, C. and Zhang, J. (1997) A Simple Endogenous Growth Model with Endogenous Fertility: Indeterminacy and Uniqueness. Journal of Population Economics 10, 97-100.

Zhang, W.B. (1993) Woman's Labor Participation and Economic Growth - Creativity, Knowledge Utilization and Family Preference. Economics Letters 42, 105-10.

Zhang, W.B. (2012) Economic Growth with Heterogeneous Households, Gender Division of Labor, and Elastic Labor Supply. Journal of Income Distribution 21, 15-37.

Zhang, W.B. (2014) Endogenous Population with Human and Physical Capital Accumulation International Review of Economics (forthcoming).

Appendix on line at the Journal Website. English: http:// https:/ ideas.repec.org/ s/ sdo/ regaec.html Galego: http:/ / www.usc.es/ econo/ RGE/ benvidag.htm 


\section{Appendix 1. Figuras.}
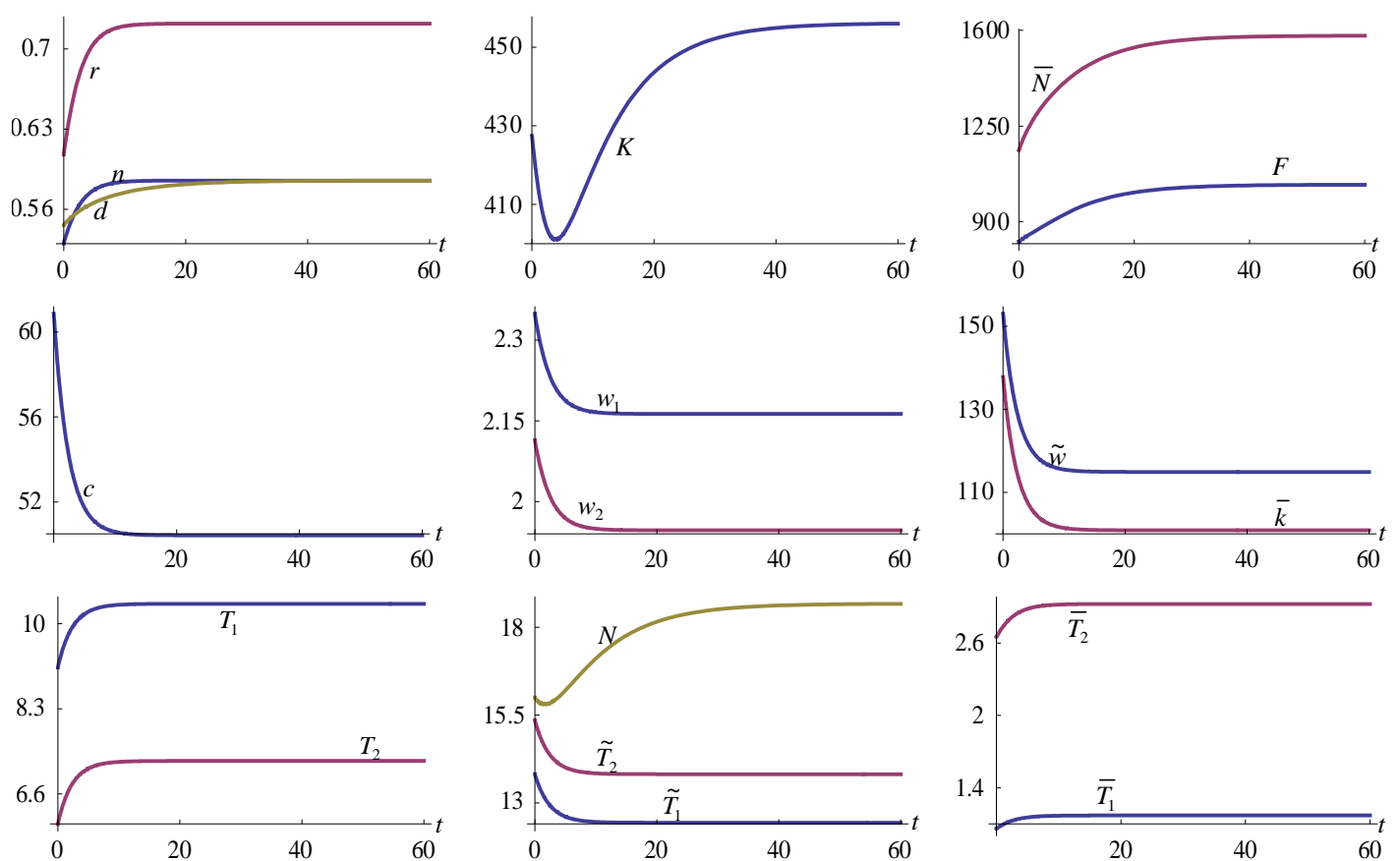

Figura 1. Movementos do sistema económico
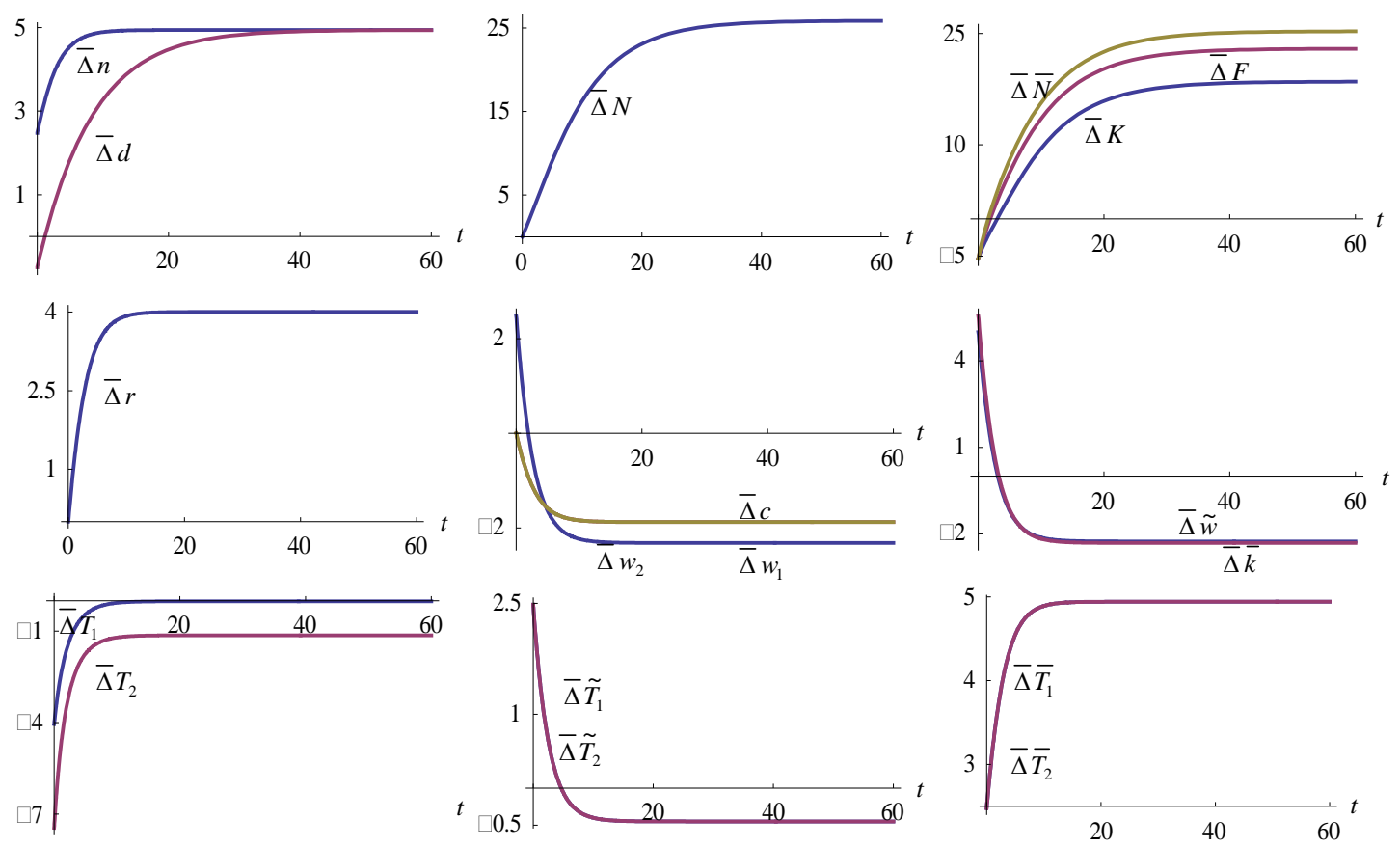

Figura 2. Aumento na tendencia a ter fillos 

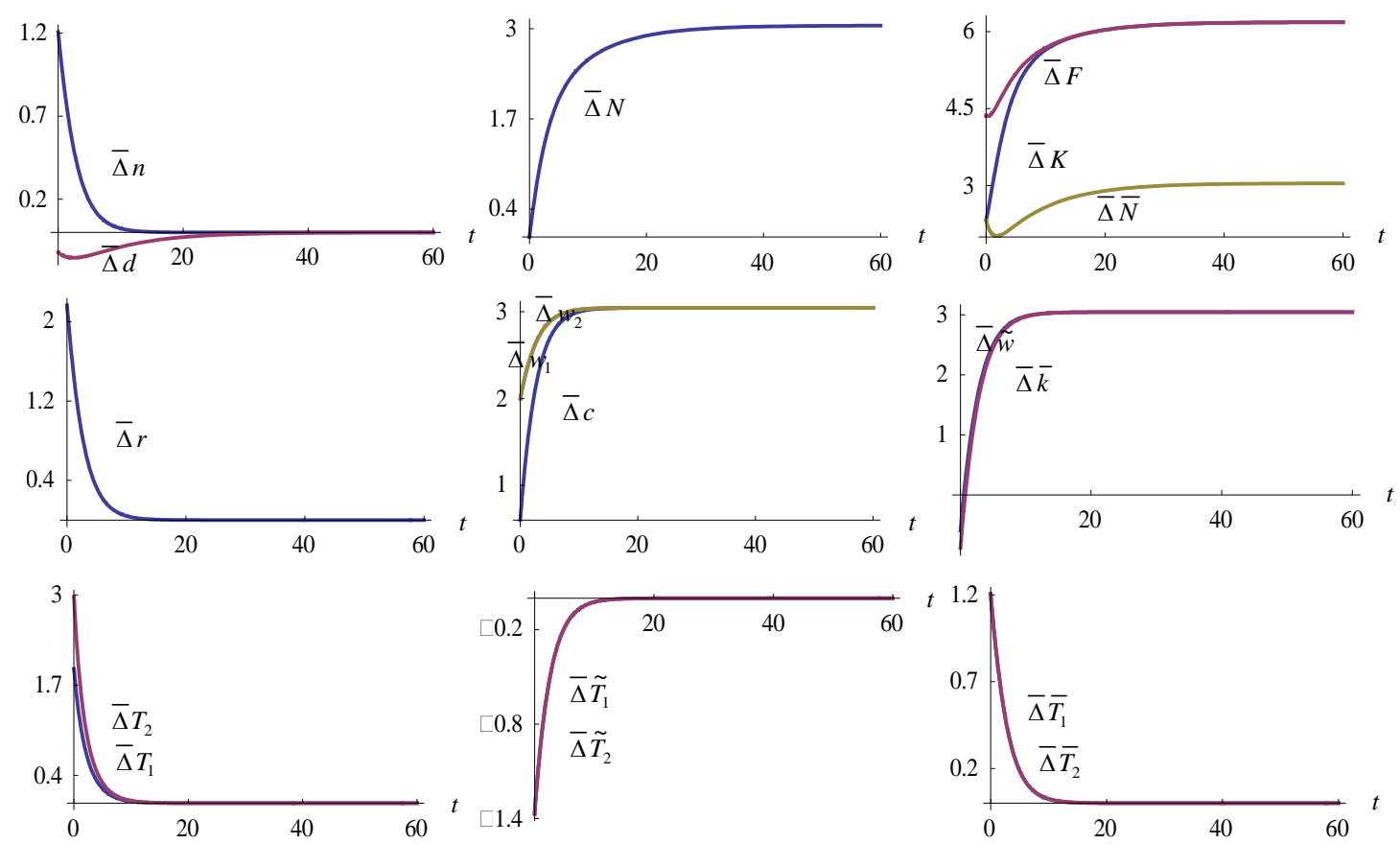

Figura 3. Aumento na produtividade total dos factores
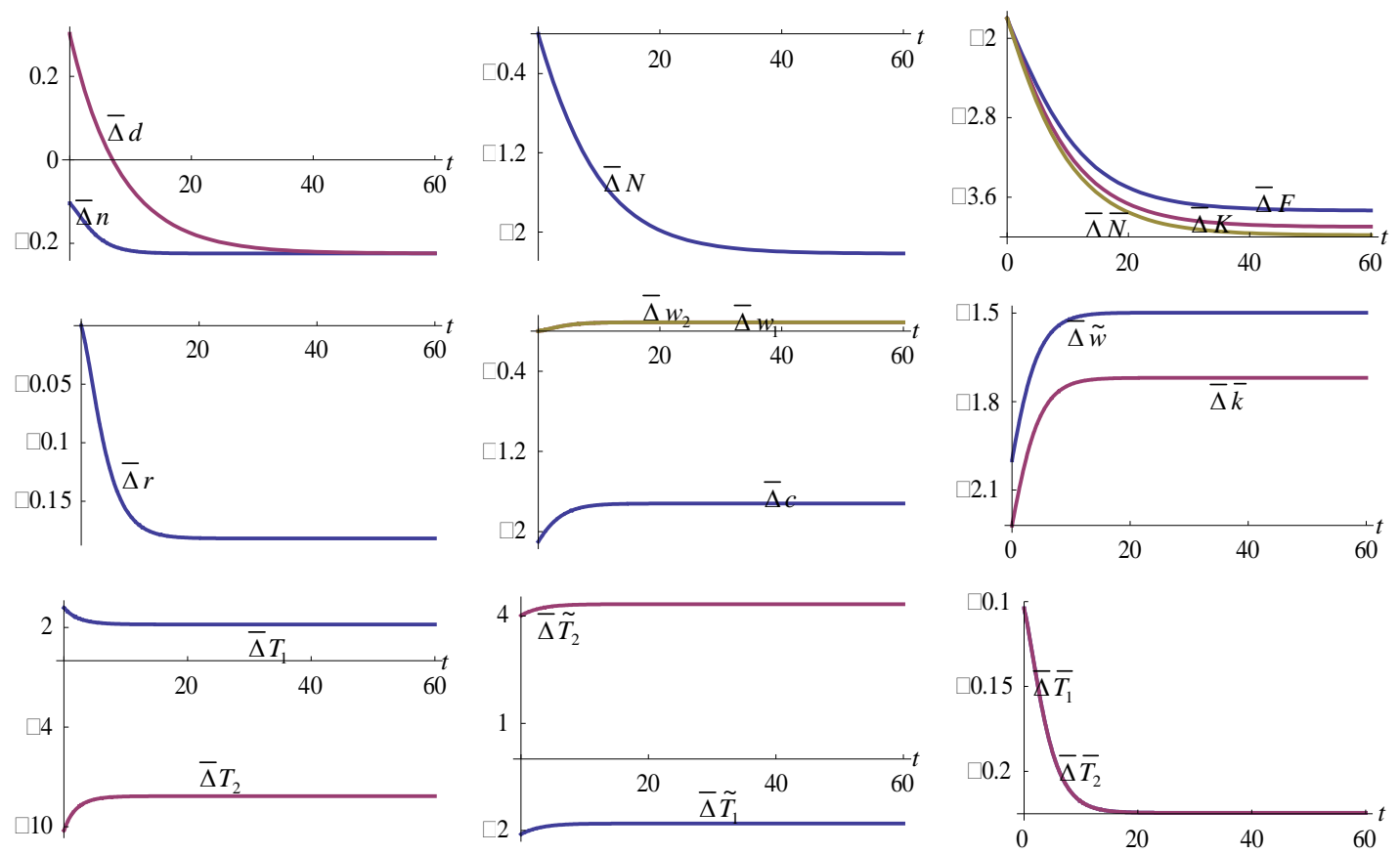

Figura 4. Aumento na tendencia das mulleres a realizar actividade de lecer 

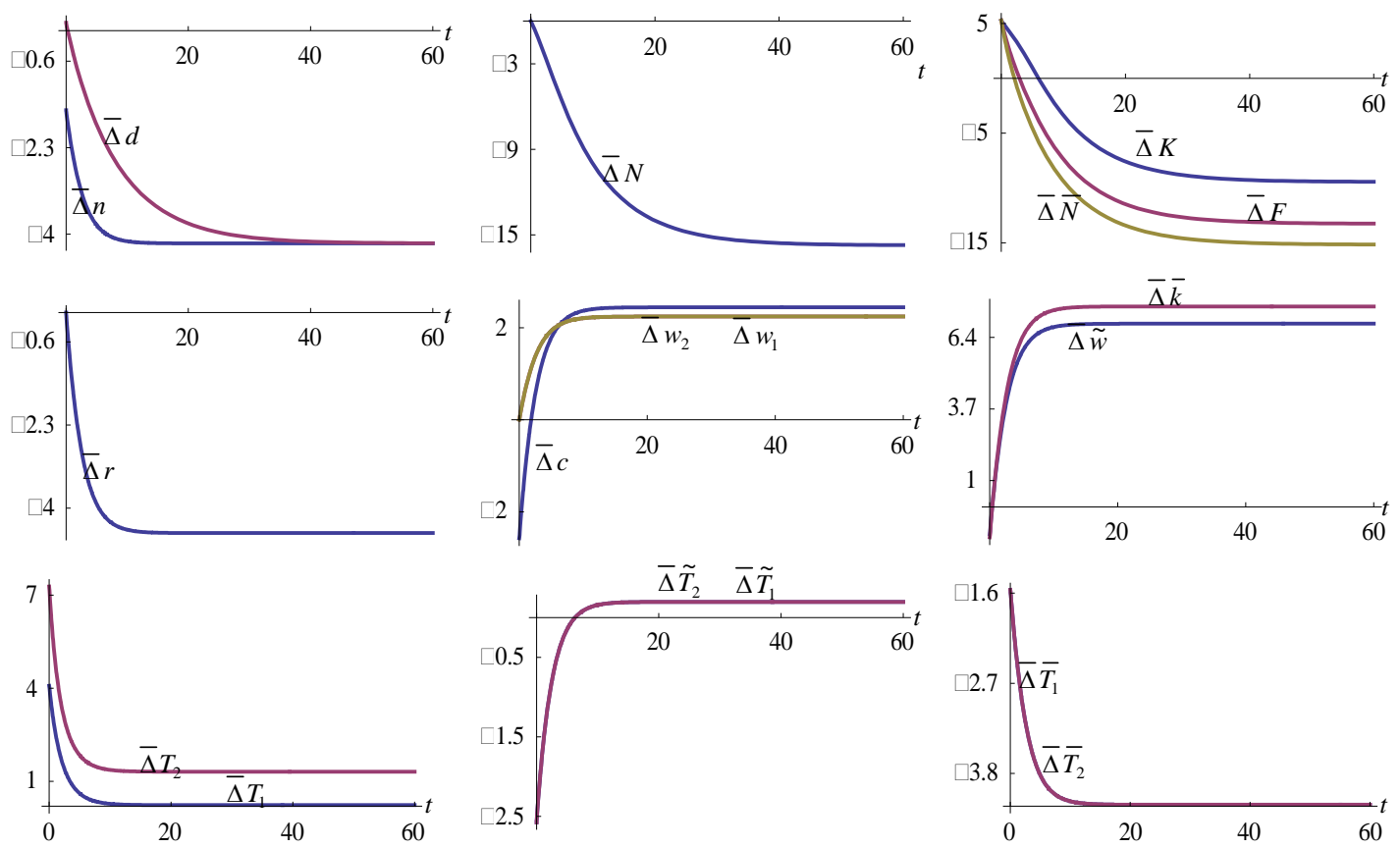

Figura 5. Aumento da tendencia ao aforro
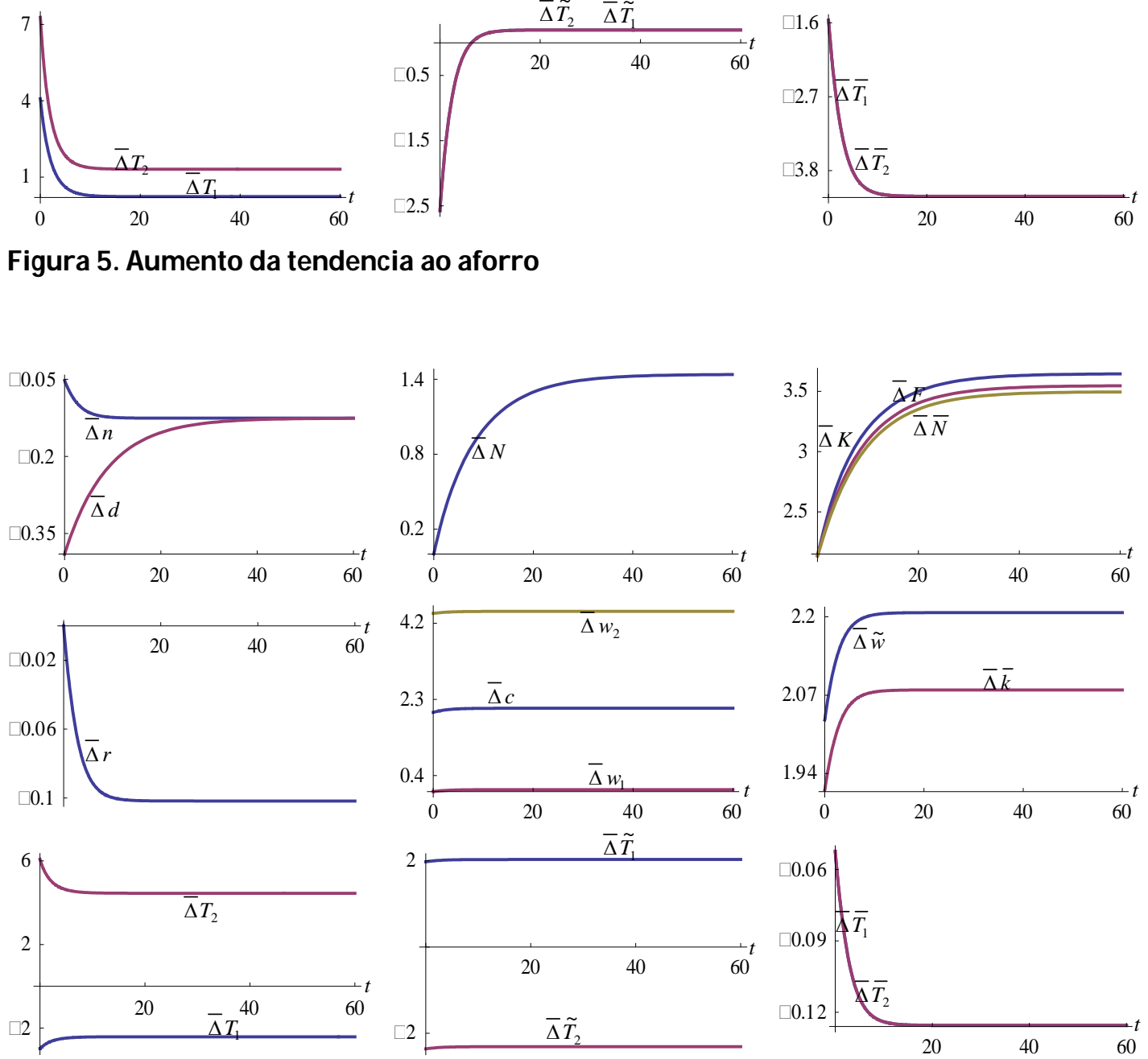

Figura 6. A mellora do capital humano das mulleres 

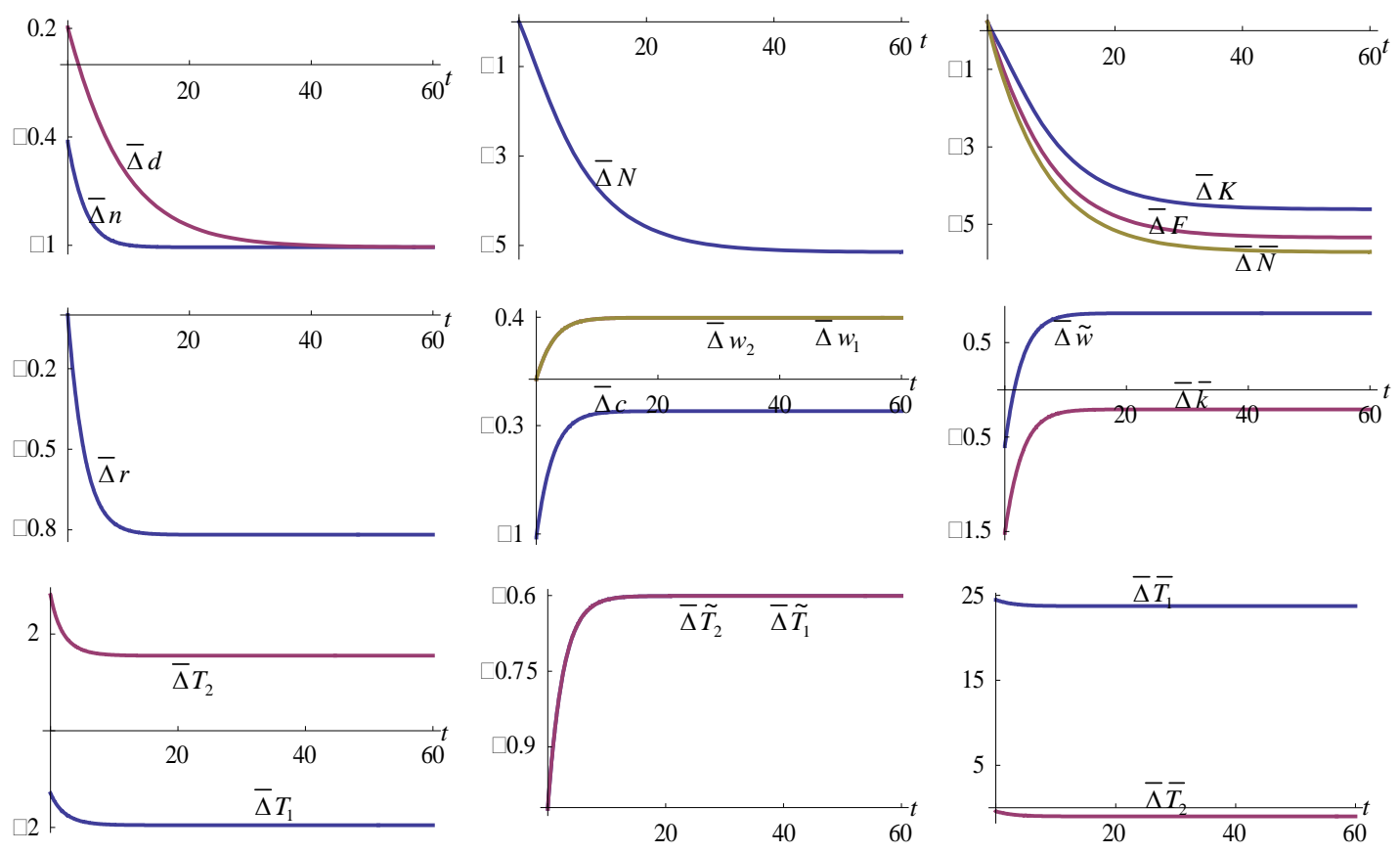

Figure 7. Máis tempo adicado á crianza dos fillos polos pais

Apéndice: Extensións e limitacións

Unha limitación evidente no noso modelo é que a función do coidado dos fillos amosa un redemento a escala constante en canto ao tempo que os pais e as nais adican ao coidado dos fillos. É posible xeneralizar o noso modelo aplicando funcións máis xenéricas de produción e utilidade. A nosa investigación tamén se pode estender e xeneralizar ao estudo dalgúns fenómenos relacionados co xénero, o capital humano e o desenvolvemento económico. Por exemplo, Stotsky (2006) identifica unha serie de fenómenos relacionados coas diferenzas de xénero e o comportamento da economía: (1) as diferenzas de xénero afectan as variables macroeconómicas, como o consumo agregado e os aforros; (2) o goberno pode reaccionar ante cambios sociais e económicos; (3) as mulleres tenden a adicar unha maior proporción dos recursos do fogar ás necesidades básicas e ao coidado dos fillos; (4) as mulleres teñen maior tendencia ao aforro e a investir en actividades produtivas e amosan prudencia na forma de aforrar e investir; (5) a falta de acceso da muller á educación e a outras oportunidades económicas e sociais, todas elas en relación aos homes, inhiben o crecemento económico. Para explicar estes fenómenos, debemos refinar o noso modelo. Outra aportación importante sería engadir os aparellos domésticos ao modelo. Conforme a Bar e Leukhina (2011) tanto as diferenzas de ingresos por xénero e o custo dos aparellos domésticos son necesarios para entender a evolución da distibución do tempo da muller casada ao longo do tempo. No marco analítico dun modelo de crecemento endóxeno de tipo expansivo, Bucci (2013) analiza as correlacións entre o crecemento das taxas da poboación e da economía. A análixe conclúe que o crecemento da poboación e o crecemento da produtividade están correlacionados de forma ambigua en referencia á crecente tendencia á especialización. Convén expandir o noso marco analítico para incluír algunhas das forzas económicas e factores da poboación. Tamén sería interesante xeneralizar o modelo dentro do marco de sectores heteroxéneos (p. ex., Uzawa, 1961, 1963; Galor, 1992; Harrison, 2003; Jensen, 2003; Cremers, 2006; Herrendorf e Valentinyi, 2006; Li e Lin, 2008; Stockman, 2009; e Jensen e Lehmijoki, 2011). 